\title{
KÊT QUẢ BƯỚC ĐẦU ĐÁNH GIÁ TÁC ĐỘNG CỦA BIẾN ĐỔI KHÍ HẬU ĐỐI VỚI NGHỀ CÁ BIỂN VIÊTT NAM BẰNG PHƯƠNG PHÁP HÀM SẢN XUẤT
}

\author{
Nguyễn Ngọc Thanh ${ }^{1}$, Nguyễn Viết Thành ${ }^{2 *}$, Dư Văn Toán ${ }^{3}$, Ngô Thọ Hùng ${ }^{4}$ \\ ${ }^{1}$ Đại học Tài Nguyên và Môi trường Hà Nội, Việt Nam \\ ${ }^{2}$ Trường Đại học Kinh tế-Đại học Quốc gia Hà Nội, Việt Nam \\ ${ }^{3}$ Tổng cục Biển và Hải Đảo Việt Nam, Việt Nam \\ ${ }^{4}$ Công Ty Cổ Phần Đầu Tư Và Phát Triển Hòa Phong E\&C, Việt Nam \\ "E-mail: thanhmpa@gmail.com
}

Ngày nhận bài: 16-12-2013

\begin{abstract}
TÓM TĂT: Nghiên cứu này đánh giá tác động của biến đổi khí hậu đối với khai thác thủy sản Việt Nam. Hàm sản xuất được sủ dụng trong nghiên cứu để mô hình hóa tác động của biến đổi khí hậu đối với sản luợng khai nhằm đánh giá tác động của biến đổi khi hậu đối với nghề cá biểnViệt Nam. Dũ liệu theo chuỗi thời gian tù 1976 đến 2010 của sản luợng khai thác, cuờng lực khai thác, lao động nghề cá, luợng mua trung bình, nhiệt độ trung bình, số lượng bão hàng năm đã được thu thập và phân tích. Kết quả nghiên cứu ban đầu cho thấy luợng mưa trung bình hàng năm khu vực ven biển có tác động tiêu cực đến sản lượng khai thác hải sản của Việt Nam. Tuy vậy ảnh huởng của việc tăng luợng mura đối với sản luợng khai thác hải sản là tuơng đối nhỏ so với các yếu tố khác được nghiên cứu nhu cường lục khai thác và lao động nghề cá.
\end{abstract}

Tù khóa: Biến đổi khi hậu, nghề cá biển Việt Nam, hàm sản xuất.

\section{GIỚI THIỆ}

Các nghiên cứu khoa học đã chỉ ra rằng biến đổi khí hậu là một mối đe dọa nghiêm trọng trên phạm vi toàn cầu và đòi hỏi tất cả các nước phải cùng nhau hành động để phòng ngừa và ngăn chặn các tác động tiêu cực do biến đổi khí hậu gây ra. Theo kêt quả nghiên cứu của Stern [12], nếu các nước không có hành động để đối phó với biến đổi khí hậu thì thiệt hại do biến đổi khí hậu gây ra ước tính vào khoảng $5-20 \%$ GDP toàn cầu mỗi năm, trong khi đó chi phí để giảm khí thải gây hiệu ứng nhà kính nhằm ngăn chặn tác động tiêu cực của biến đổi khí hậu chỉ vào khoảng $1 \%$ GDP toàn cầu mỗi năm. Kết quả nghiên cứu của Yusuf và Francisco [15] cho thấy, Việt Nam là một trong những nước rất dễ bị tồn thương bởi tác động của biến đổi khí hậu trong khu vực
Đông Nam Á. Việt Nam đứng thứ 6 trong bảng xếp hạng toàn cầu chỉ số rủi ro do biến đổi khí hậu (CRI) giai đoạn 1991-2010 [9]. Việt Nam cũng đứng thứ 23 trong bảng xếp hạng toàn cầu chỉ số tổn thương do biến đổi khí hậu gây ra trong 30 năm tới [11]. Theo các kịch bản về biến đổi khí hậu cho Việt Nam [4], đến cuối thế kỷ 21 , khí hậu trên tất cả các vùng của Việt Nam sẽ có nhiều thay đổi, tổng lượng mưa năm và lượng mưa mùa mưa tăng trong khi lượng mưa mùa khô lại giảm. Ngoài ra, mực nước biển sẽ dâng lên khoảng $75 \mathrm{~cm}$ so với trung bình thời kỳ 1980 - 1999. Tuy chưa có đánh giá thiệt hại do biến đổi khí hậu gây ra, nhưng thiệt hại do các hiện tượng thời tiết bất thường như bão, lũ và triều cường gây ra là đáng kể đổi với Việt Nam hàng năm. Theo kết quả nghiên cứu của Lê Trường Giang [8], trong khoảng thời gian từ 1994 đến 2003, thiệt hại trung bình do 
thiên tai gây ra đối với Việt Nam vào khoảng gần 250 triệu đôla mỗi năm, chiếm khoảng $0,8 \%$ GDP trung bình trong cùng khoảng thời gian này.

Thủy sản là ngành kinh tế quan trọng trong nền kinh tế Việt Nam, theo thông kê [14], giá trị xuất khẩu thủy sản đã tăng gấp ba lần trong 10 năm qua và đã đạt hơn 6,1 tỉ đôla năm 2011 . Tuy nhiên, thủy sản lại là ngành chịu nhiều ảnh hưởng từ các hiện tượng thời tiết bất thường. Chỉ tính riêng cơn bão Linda năm 1997 đã làm chìm và hư hại gần 2.000 tàu thuyền khai thác thủy sản, gây thiệt hại khoảng 136.000 hecta diện tích nuôi trồng thủy sản và hơn 34.000 tấn thủy hải sản [3]. Ngoài ra, với hàng triệu lao động trực tiếp và gián tiếp tham gia hoạt động sản xuất thủy sản, chủ yếu sống ở khu vực ven biển, ngành thủy sản Việt $\mathrm{Nam}$ rất dễ bị tổn thương bởi các tai biến thiên nhiên và nước biển dâng do biến đổi khí hậu gây ra. Do vậy, việc nghiên cứu tác động của biến đổi khí hậu đối với thủy sản là hết sức cần thiết nhằm xác định các yếu tố và mức độ tác động của biến đổi khí hậu với thủy sản để làm cơ sở xây dựng các biện pháp ứng phó phù hợp.

Nghiên cứu này đánh giá tác động của biến đổi khí hậu đối với khai thác thủy sản Việt Nam. Hàm sản xuất được sử dụng trong nghiên cứu để mô hình hóa tác động của biến đổi khí hậu đối với sản lượng khai thác thuỷ sản nhằm đánh giá tác động của biến đổi khí hậu đối với khai thác thủy sản của Việt Nam. Cấu trúc nghiên cứu này được trình bày như sau: phần tiếp theo mô tả phương pháp sử dụng hàm sản xuất trong nghiên cứu tác động của biến đổi khí hậu. Phần kế tiếp mô tả dữ liệu và cuối cùng là phần kết quả và thảo luận.

\section{PHƯONG PHÁP NGHIÊN CỨU}

\section{Mô hình hàm sản xuất}

Phương pháp tiếp cận thay đổi năng suất (change-in-productivity approach - CP) còn được gọi là phương pháp hàm sản xuất (the production-function method), tiếp cận tác động lên sản xuất (effect on production approach), hay định giá môi trường như là một đầu vào (valuating environment as an input) tìm cách khai thác mối quan hệ giữa các thuộc tính môi trường và mức sản lượng của một hoạt động kinh tế [5]. Giả định cơ bản là, khi một thuộc tính môi trường được đưa vào hàm sản xuất của một doanh nghiệp, tác động kinh tế do thay đổi môi trường có thể được đo bằng cách xem xét hiệu quả sản xuất và xác định giá trị của tác động theo giá thị trường đầu ra của sản phẩm. Đây là phương pháp lượng giá gián tiếp, không dựa vào đường cầu (như phương pháp chi phí du lịch hay giá hưởng thụ), vì vậy số tiền ước tính nên được hiểu là một chỉ thị (không phải giá trị thực sự) do tác động của thay đồi môi trường tới phúc lợi cuối cùng. Phương pháp tiếp cận hàm sản xuất đã được sử dụng rộng rãi, đặc biệt là để đánh giá những tác động của sự thay đổi chất lượng môi trường (ví dụ như mưa axit, ô nhiễm nước) vào nông nghiệp [1] và thủy sản [10]. Ví dụ khác về ứng dụng bao gồm phân tích tác động của dòng chảy [2] và xác định giá trị lợi ích bảo vệ của vùng đất ngập nước ven biển chống lại thiệt hại do bão gây ra [7]. Theo Barbier, phương pháp hàm sản xuất phù hợp để áp dụng cho các nước đang phát triển bởi vì sự phụ thuộc trực tiếp của nhiều hệ thống sản xuất ở các nước này đối với tài nguyên thiên nhiên và các chức năng sinh thái. Một cách khái quát, phương pháp tiếp cận hàm sản xuất bao gồm một quy trình hai bước. Bước đầu tiên là xác định các tác động vật lý của sự thay đổi môi trường lên hoạt động sản xuất. Bước thứ hai là lượng giá những tác động này dựa trên đầu ra của hoạt động sản xuất. Rõ ràng, ở giai đoạn đầu tiên, hợp tác là cần thiết giữa các nhà khoa học tự nhiên, kinh tế và các nhà nghiên cứu khác, để xác định bản chất của các mối liên hệ giữa các yếu tố môi trường và hoạt động sản xuất $[7,10]$. Gọi Y là đầu ra của hoạt động sản xuất, ENV là biến môi trường quan tâm, $X_{i} \ldots X_{k}$ là các biến đầu vào khác của hoạt động sản xuất, hàm sản xuất của một doanh nghiệp hay một ngành sản xuất có thể được mô tả bằng công thức (1):

$$
\mathrm{Y}=\mathrm{f}\left(\mathrm{X}_{\mathrm{i} \ldots} \ldots \mathrm{X}_{\mathrm{k}}, \mathrm{ENV}\right)
$$

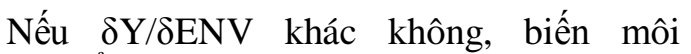
trường thể hiện qua ENV (ví dụ như tăng hoặc giảm nhiệt độ, lượng mưa) với điều kiện các yếu tố khác không đổi,sẽ làm giảm/tăng mức sản lượng. Nhìn chung, khi sản lượng đầu ra $\mathrm{Y}$ là một hàng hóa thị trường, và giá cả có thể quan sát được và không bị ảnh hưởng bởi các 
yếu tố liên quan ngoài thị trường, mức giá này có thể được sử dụng để ước tính giá trị của một sự thay đổi do tác động của các yếu tố mồi trường (qua biến ENV). Ngoài ra, giá trị này cũng có thể được ước tính bằng cách xem xét những thay đổi của thị trường các yếu tố đầu vào $\left(\mathrm{X}_{\mathrm{i}} \ldots \mathrm{X}_{\mathrm{k}}\right)$ cần thiết để duy trì sản lượng đầu ra ở một mức độ nhất định. Trong nghiên cứu này mô hình hàm sản xuất với các biến đầu vào truyền thống được sử dụng trong nghề cá $[6$, 11] dưới dạng logarit được mô tả trong phương trình (2):

$$
\ln (Y)=\beta_{0}+\sum_{i=1}^{k} \beta_{i} \ln \left(X_{i}\right)+\sum_{j=k+1}^{n} \beta_{j} C C_{j}
$$

Trong đó $\mathrm{CC}_{\mathrm{j}}$ - là các biến liên quan đến Môn hình hàm sản xuất có dạng (3) sau: biến đổi khí hậu.

$$
\begin{aligned}
\ln \left(\text { catch }_{t}\right)=\beta_{0} & +\beta_{1} T+\beta_{2} \ln \left(\text { capacity }_{t}\right)+\beta_{3} \ln (\text { labour })+\beta_{4} \text { Rain } \\
& +\beta_{\mathrm{s}} \text { typhoon } n_{t}+\beta_{\mathrm{t}} \text { Temp }_{t}
\end{aligned}
$$

Catch $_{\mathrm{t}}=$ sản lượng khai thác (tấn) năm $\mathrm{t}$.

Capacity $\mathrm{y}_{\mathrm{t}}=$ cường lực khai thác của đội tàu $(1.000 \mathrm{CV})$ năm theo thời gian năm $\mathrm{t}$.

Labour $_{\mathrm{t}}=$ số lượng người tham gia khai thác hải sản năm theo thời gian năm $t$.

Rain $_{\mathrm{t}}=$ lượng mưa trung bình năm $\mathrm{t}(\mathrm{mm})$. $\left({ }^{0} \mathrm{C}\right)$.

$\mathrm{Temp}_{\mathrm{t}}=$ nhiệt độ mặt biển trung bình năm $\mathrm{t}$

Hurricane $_{\mathrm{t}}=$ số lượng cơn bão biển năm $\mathrm{t}$ (sức gió mạnh hơn $100 \mathrm{~km} / \mathrm{h}$ ).

$\mathrm{T}=\mathrm{xu}$ hướng thời gian.

$$
\beta_{\mathrm{i}, \mathrm{j}}=\text { các hệ số thực nghiệm. }
$$

\section{Dũ̃ liệu}

Dữ liệu sử dụng cho mô hình được thu thập từ các nguồn thống kê của Bộ Nông nghiệp và Phát triển Nông thôn, Bộ Tài nguyên và Môi trường và Tổng cục Thống kê $[4,12,13]$. Dũ liệu theo chuỗi thời gian từ 1976 đến 2010 của sản lượng khai thác, cường lực khai thác, lao động nghề cá, lượng mưa trung bình, nhiệt độ trung bình, số lượng bão hàng năm đã được thu

\begin{tabular}{|c|c|c|c|c|c|}
\hline Các biến & $\begin{array}{l}\text { Mẫu thu thập } \\
\text { (năm) }\end{array}$ & $\begin{array}{l}\text { Giá trị trung } \\
\text { bình }\end{array}$ & $\begin{array}{l}\text { Độ lệch } \\
\text { chuẩn }\end{array}$ & $\begin{array}{c}\text { Giá trị nhỏ } \\
\text { nhất }\end{array}$ & $\begin{array}{c}\text { Giá trị lớn } \\
\text { nhất }\end{array}$ \\
\hline $\begin{array}{l}\text { Sản lượng } \\
\text { (tấn) }\end{array}$ & 35 & 1.073 .771 & 626.058 & 377.192 & 2.420 .800 \\
\hline $\begin{array}{l}\text { Lao động } \\
\text { (người) }\end{array}$ & 35 & 665.872 & 566031 & 190.399 & 1.767 .000 \\
\hline $\begin{array}{l}\text { Cường lực } \\
\text { (CV) }\end{array}$ & 35 & 2.082 .611 & 1.883 .244 & 453.871 & 6.123 .000 \\
\hline $\begin{array}{l}\text { Lượng mưa } \\
\text { (mm) }\end{array}$ & 35 & $1.793,79$ & 246 & $1.311,33$ & $2.288,60$ \\
\hline Nhiệt độ ( $\left.{ }^{\circ} \mathrm{C}\right)$ & 35 & 25,72 & 0,34 & 25,23 & 26,67 \\
\hline Bão (cơn bão) & 34 & 1,41 & 1,37 & 0 & 5 \\
\hline
\end{tabular}
thập và phân tích. Các dữ liệu này được mô tả trong bảng 1 .

Bảng 1. Mô tả dữ liệu sử dụng trong nghiên cứu (1976-2010)

\section{KẾT QUẢ VÀ THẢO LUẬN}

Bảng 2 mô tả kết quả tính toán ban đầu mô hình hàm sản xuất đối với nghề cá của Việt
Nam với dữ liệu theo chuỗi thời gian từ 1976 đến 2010. 
Kết quả bước đầu đánh giá tác động ...

Bảng 2. Ước lượng hàm sản xuất cho nghề cá Việt Nam với dữ liệu từ 1976-2010

\begin{tabular}{clll}
\hline Ký hiệu & \multicolumn{1}{c}{ Các biến } & \multicolumn{1}{c}{ Ước lượng (độ lệch chuẩn) } \\
\cline { 2 - 3 }$\beta_{0}$ & Hệ số & $9,39^{*}(1,58)$ \\
$\beta_{1}$ & Xu hướng thời gian $(T)$ & $0,009(0,005)$ \\
$\beta_{2}$ & Cường lực (capacity) & $0,23(0,14)$ \\
$\beta_{3}$ & Lao động (labour) & $0,31^{*}(0,13)$ \\
$\beta_{4}$ & Lượng mưa (rain) & $-0,00022^{*}(0,0000698)$ \\
$\beta_{5}$ & Nhiệt độ (temperature) & $-0,1056(0,064)$ \\
$\beta_{6}$ & Số lượng bão (hurricane) & $-0,0016(0,0011)$ \\
& $R^{2}$ & 0,97 \\
& F statistic & 216 \\
& DW statistic & 1,31 \\
\hline
\end{tabular}

Biến phu thuộc là $\ln ($ Catch), $n=34, * p<0,01$.

Kiểm định Durbin-Watson (DW) để xem xét hiện tượng tự tương quan bậc một của mô hình với mức ý nghĩa $5 \%\left(n=34, \mathrm{k}^{\prime}=6\right)$ cho thấy giá trị thống kê $(\mathrm{d})$ nằm trong khoảng giới hạn cao $(1,89)$ và thấp $(1,08)$, thuộc miền không kết luận. Tuy nhiên, kiểm định thay thế (the
Durbin's alternative test - durbinalt) và kiểm định tự tương quan bậc cao hơn (BreuschGodfrey) cho thấy khổng có hiện tượng tự tương quan trong mô hình đã ước lượng với mức ý nghĩa $5 \%$ (các kết quả kiểm định được trình bày tại hình 1 và bảng 3 ).

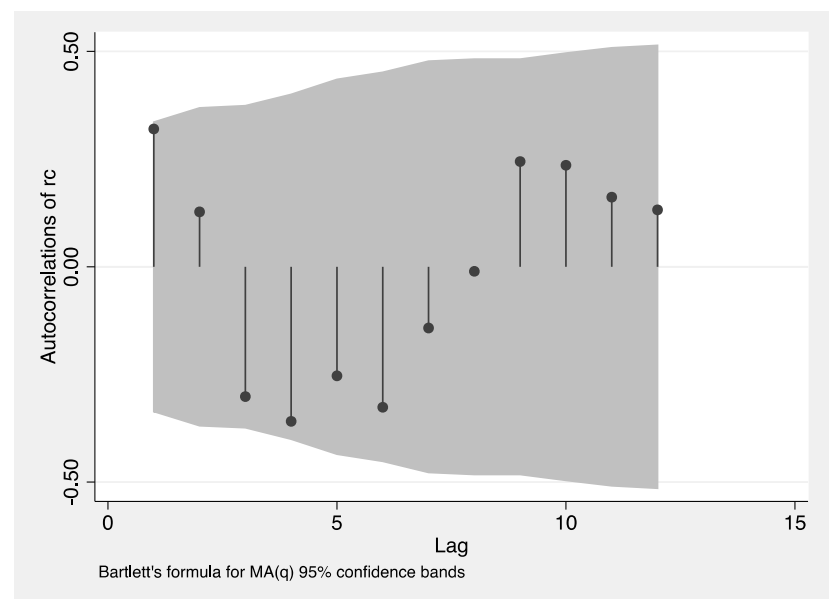

Hình 1. Biểu đồ kết quả kiểm định tự tương quan của mô hình ước lượng

Bảng 3. Trình bày các kiểm định đối với mô hình đã ước lượng

\begin{tabular}{|c|c|c|c|}
\hline Kiểm định & Giá trị quan sát & Giá trị xác suất & Ghi chú \\
\hline $\begin{array}{l}\text { Durbin's alternative test - } \\
\text { durbinalt }\end{array}$ & 3,22 & 0,073 & $\begin{array}{l}\text { Không bác bỏ giả thuyết } \mathrm{H}_{0} \text { : "không có } \\
\text { tự tương quan" }\end{array}$ \\
\hline Breusch-Godfrey test & 3,75 & 0,053 & $\begin{array}{l}\text { Không bác bỏ giả thuyết } \mathrm{H}_{0} \text { : "không có } \\
\text { tự tương quan" }\end{array}$ \\
\hline Ramsey RESET test & 2,18 & 0,116 & $\begin{array}{l}\text { Không bác bỏ giả thuyết } \mathrm{H}_{0} \text { : "mô hình } \\
\text { có dạng hàm đúng" }\end{array}$ \\
\hline Breusch-Pagan & 0,06 & 0,811 & $\begin{array}{l}\text { Không bác bỏ giả thuyết } \mathrm{H}_{0} \text { : "mô hình } \\
\text { không có phương sai sai số thay đổi" }\end{array}$ \\
\hline
\end{tabular}


Từ kết quả phân tích định lượng, sự phụ thuộc của sản lượng khai thác đối với biến đầu vào và biến liên quan đến biến đổi khí hậu được chúng tôi tìm được công thức tính toán ra cho nghề cá vùng biển Việt Nam:

\section{$\ln (\overrightarrow{\text { catch }})=9,38+0,09 \mathrm{~T}+0,23 \ln ($ capacity $)+0,00022$ Rain $+0,1056 \mathrm{Temp}$ $-0,0016$ typhoon}

Kết quả ước lượng bước đầu cho thấy nếu lao động khai thác thủy sản tăng $1 \%$ thì sản lượng khai thác sẽ tăng $0,31 \%$. Kết quả cũng cho thấy nếu lượng mưa trung bình hàng năm khu vực ven biển tăng lên $100 \mathrm{~mm}(0,1 \mathrm{~m})$ thì sản lượng khai thác sẽ giảm khoảng 2,2\%. Kết quả này phù hợp với thực tế vì tăng lượng mưa có thể giảm cường lực khai thác và phá hủy cơ sở hạ tầng nghề cá ven biển. Tuy vậy ảnh hưởng của việc tăng lượng mưa đối với sản lượng khai thác là tương đối nhỏ. Như mong đợi, tăng nhiệt độ trung bình và số lượng cơn bão lớn hàng năm có thể ảnh hưởng tiêu cực đến sản lượng khai thác. Mô hình cho thấy xu thế thời gian gia tăng đối với sản lượng khai thác nhưng cần có nhiều dữ liệu thống kê chi tiết và liên tục hơn.

Để có những nhận định chính xác hơn về tác động của biến đổi khí hậu đối với khai thác thủy sản, dữ liệu nhiệt độ mặt biển và một số biến chính sách cần được thu thập và đưa vào mô hình. Ước lượng tác động của biến đổi khí hậu đối với nghề cá ở các khu vực khác nhau (khu vực miền Bắc, Trung Bộ và Nam Bộ) cũng cần được nghiên cứu. Ngoài ra, việc qui định các mô hình khác nhau, lựa chọn mô hình phù hợp cho mỗi vùng và lượng giá tác động của biến đổi khí hậu đồi với nghề cá ở các khu vực khác nhau theo các kịch bản biến đổi khí hậu cũng cần được nghiên cứu sâu hơn.

\section{KẾT LUẬN}

Nghiên cứu này sử dụng hàm sản xuất để đánh giá tác động của biến đổi khí hậu đối với khai thác thủy sản Việt Nam. Các biến_sản lượng khai thác, cường lực khai thác, lao động nghề cá, lượng mưa trung bình, nhiệt độ trung bình, số lượng bão hàng năm đã được thu thập và phân tích. Kết quả ước lượng bước đầu cho thấy nếu lao động khai thác thủy sản tăng $1 \%$ thì sản lượng khai thác sẽ tăng $0,31 \%$. Kêt quả cũng cho thấy nếu lượng mưa trung bình hàng năm khu vực ven biển tăng lên 100 mm $(0,1 \mathrm{~m})$ thì sản lượng khai thác sẽ giảm khoảng 2,2\%. Ngoài ra, việc tăng nhiệt độ trung bình và số lượng cơn bão lớn hàng năm cũng có thể ảnh hưởng tiêu cực đến sản lượng khai thác và xu thế thời gian có thể gia tăng đối với sản lượng khai thác. Tuy vậy các tác động này không có ý nghĩa về mặt thống kê vì vậy cần có thêm dữ liệu thống kê để phân tích và kiểm định trước khi có các kết luận chính xác hơn.

\section{TÀI LIỆU THAM KHẢO}

1. Adam, R. M., J. M. Callaway and B. A. McCarl, 1986. "Pollution, Agriculture and Social Welfare: The Case of Acid Deposition". Canadian Journal of Agricultural Economics/Revue canadienne d'agroeconomie, 34(1): 3-19.

2. Barbier, E. B., 1998. Environmental Project Evaluation in Developing Countries: Valuing the Environment as Input. World Congress of Environmental and Resource Economists. Venice.

3. http://www.ccfsc.gov.vn/resources/ccfsc/images/download/Bao\%20so\%205\%20(Linda) \%20nam\%2097_07117164939.pdf. Tổng hợp thông tin thiệt hại do bão số năm ngày 2/11/1997 gây ra.

4. Bộ Tài nguyên và Môi trường, 2012. Kịch bản biến đối khí hậu, nước biển dâng cho Việt Nam. Nxb. Tài nguyên môi trường và bản đồ Việt Nam. Hà Nội. 33 tr.

5. Dosi, C., 2001. Environmental Values, Valuation Methods, and Natural Disaster Damage Assessment, Environment and Human Settlements Division, United Nation.

6. Eide, A., F. Skjord, F. Olsen and $O$. Flaaten, 2003. "Harvest functions: The 
Norwegian bottom trawl cod fisheries". Marine Resource Economics, 18.

7. Farber, S., 1987. "The value of coastal wetlands for protection of property against hurricane wind damage". Journal of Environmental Economics and Management, 14(2): 143-151.

8. Le Truong Giang, 2005. Damage cause by strong win and wind loads standard for building in Vietnam. Kanagawa, Tokyo Polytechnic University: 29.

9. Harmeling, S., 2012. Global climate risk index 2012: who suffers most from extreme weather events? weather-related loss events in 2010 and 1991 to 2010. Bonn, Germany, Germanwatch: 28 pp.

10. Kahn, J., 1991. Atrazine Pollution and Cheasepeake Fisheries. Farming and the Countryside: An Economic Analysis of
External Costs and Benefits. N. Hanley. Oxford, CAB International.

11. Maplecroft, 2012. Climate Change Vulnerability Index 2012.

12. Stern, N., 2007. The Economics of Climate Change: The Stern Review. Cambridge, Cambridge University Press.

13. Nguyen Viet Thanh, 2011. "Sustainable management of the shrimp trawl fishery in Tonkin Gulf, Vietnam". Applied Economics Journal, 18(2): 65-81.

14. Tổng cu Thống kê, 2012. Niên giám Thống kê. Nhã xuất bản Thống Kê. Hà Nội.

15. Yusuf, A. A. and H. A. Francisco, 2009. Climate Change Vulnerability Mapping for Southeast Asia. Singapore, Economy and Environment Program for Southeast Asia (EEPSEA): 26. 
Nguyễn Ngọc Thanh, Nguyễn Viết Thành, ...

\title{
PREMILINARY ESTIMATION RESULTS OF IMPACT OF CLIMATE CHANGE ON MARINE FISHERIES IN VIETNAM BY USING PRODUCTION FUNCTION
}

\author{
Nguyen Ngoc Thanh ${ }^{1}$, Nguyen Viet Thanh ${ }^{2}$, Du Van Toan ${ }^{3}$, Ngo Tho Hung ${ }^{4}$ \\ ${ }^{1}$ Hanoi University of Natural Resources and Environment, Vietnam \\ ${ }^{2}$ VNU University of Economics and Business, Vietnam \\ ${ }^{3}$ Vietnam Administration of Sea and Islands, Vietnam \\ ${ }^{4}$ Hoa Phong E \&C Investment and Development JSC, Vietnam
}

\begin{abstract}
This paper presents an premilinary estimation of climate change impacts on marine fishery in Vietnam. An augmented production function is used in the present study to model the effects of climate change on fishery outputs, in order to determine the impact of climate change on marine fisheries in Vietnam. The data by time series of catch, fishing effort, labour, average temperature and annual number of typhoons from 1976 to 2010 have been collected and analyzed. The preliminary results show that the annual average rainfall in coastal areas has negatively effected to Vietnam's catching production. However, the impacts of increasing rainfall on catching production are relatively smaller than those of other examined factors such as fleet capacity and labour.
\end{abstract}

Keywords: Climate change, marine fishery in Vietnam, production function. 